\title{
Experimental Study of Formation Damage during Underbalanced-Drilling in Naturally Fractured Formations
}

Siroos Salimi $^{1, *}$ and Ali Ghalambor ${ }^{2}$

1 Norwegian University of Science and Technology (NTNU)/N-7491, Trondheim, Norway

2 Oil Center Research International, Louisiana/P.O. Box 44408 Lafayette, LA 70504, USA; E-Mail: alig@louisiana.edu

* Author to whom correspondence should be addressed; E-Mail: siroos@ipt.ntnu.no; Tel.: +47-48124949; Fax: +47-73944472.

Received: 2 June 2011; in revised form: 1 September 2011 / Accepted: 17 October 2011 / Published: 24 October 2011

\begin{abstract}
This paper describes an experimental investigation of formation damage in a fractured carbonate core sample under underbalanced drilling (UBD) conditions. A major portion of this study has concentrated on problems which are often associated with UBD and the development of a detailed protocol for proper design and execution of an UBD program. Formation damage effects, which may occur even if the underbalanced pressure condition is maintained $100 \%$ of the time during drilling operation, have been studied. One major concern for formation damage during UBD operations is the loss of the underbalanced pressure condition. Hence, it becomes vital to evaluate the sensitivity of the formation to the effect of an overbalanced pulse situation. The paper investigates the effect of short pulse overbalance pressure during underbalanced conditions in a fractured chalk core sample. Special core tests using a specially designed core holder are conducted on the subject reservoir core. Both overbalance and underbalanced tests were conducted with four UBD drilling fluids. Core testing includes measurements of the initial permeability and return permeability under two different pressure conditions (underbalanced and overbalanced). Then the procedure is followed by applying a differential pressure on the core samples to mimic the drawdown effect to determine the return permeability capacity. In both UBD and short pulse OBP four mud formulations are used which are: lab oil, brine (3\% KCL), water-based mud (bentonite with XC polymer) and fresh water. The return permeability measurements show that a lab oil system performed fairly well during UBD and short $\mathrm{OB}$ conditions. The results indicate that a short overbalance pressure provides a
\end{abstract}


significant reduction in permeability of the fractured formations. In most tests, even application of a high drawdown pressure during production cannot restore the initial permeability by more than $40 \%$.

Keywords: fractured reservoir; formation damage; core flood testing; underbalanced drilling; short overbalance pressure; drilling fluid

\section{Introduction}

Minimizing formation damage that occurs during conventional drilling is a critical point for optimizing an oil field development, especially in fractured carbonate reservoirs that often exhibit low matrix permeability. Drilling fluid invasion into the fractured formation can create severe formation damage around the wellbore and reduce the productivity of the well and ultimate recovery of the field, therefore minimizing fluid invasion is very important in this type of reservoirs. The drilling operation where the drilling fluid pressure in the borehole is maintained below the pressure in the formation in the open-hole section is called underbalanced drilling (UBD). The productivity benefits of underbalanced drilling are well known in the industry. When UBD is implemented correctly, it may considerably reduce or eliminate mud invasion into the fracture systems. Even though UBD has many advantages over OBD, quantification of possible formation damage effects by comprehensive reservoir characterization and feasibility studies is central to judge the feasibility of UBD [1].

Underbalanced technology may be very successful in reducing or eliminating formation damage if properly executed, but a major portion of this study has centered on problems which are often associated with UBD and the development of detailed protocols for proper design and execution of UBD programs. Two main goals are evaluated this study, namely improving the productivity of a fractured reservoir by using UBD and reducing formation damage during UBD.

Possible formation damage effects may occur even if an underbalanced pressure condition is maintained $100 \%$ of the time during drilling operation. Another one of the major areas of sensitivity to formation damage during UBD operations is the loss of the underbalanced pressure condition. Hence, it becomes vital to evaluate the sensitivity of the formation to the effect of an overbalanced pulse situation [1].

The best way to evaluate damage potential is to test representative field fluids and core samples under simulated down-hole conditions, as is possible with dynamic formation damage (DFD) test apparatus. Unfortunately, there is very little work reported in the literature investigating formation damage in fractured reservoirs.

Jiao et al. [2] described the use of two different bridging agents, $\mathrm{CaCO}_{3}$ and acid soluble fibers, to reduce solids and invasion into a fractured Berea core sample. Their results show that the uses of fibrous additives are much more effective than granular additives such as $\mathrm{CaCO}_{3}$.

Ali et al. [3] reported successful field application of a mixture of different sizes of fiber particles to prevent lost circulation in severely depleted unconsolidated reservoirs.

Leopakke et al. [4] studied single and two particle bridging at a fracture face. They found that if the particle size is not compatible with the fracture width, a stable bridge cannot be formed and a tailored 
particle size distribution has the best plugging capabilities. Their experimental results show that a mixture of granular particles provides the best plug at fracture entrances.

The main objective of this work is the experimental study of fluid invasion in fractured carbonate reservoirs during underbalanced drilling conditions. For this purpose, chalk samples are selected as a representative of very fine-grained limestone formations to simulate in core flood testing. Mud invasion behavior under different conditions is measured. The invasion behavior of invaded fluids is influenced of many key parameters, such as overbalanced pressure and bridging additives and mud composition (polymer content), fracture size, and pore size distribution of the carbonate rock.

\section{Description of the Problem}

The high productivity of wells in naturally fractured formations is due to the presence of large and continuous fracture networks [5]. Most of the drilling mud invasion in naturally fractured reservoirs occurs in the fractures, and the invasion radius is large $\left(r_{d}>>r_{w}\right)$ because the fracture porosity is a small component of total rock porosity. Thus, filling the natural fractures with mud solids can impair the productivity. Therefore minimizing fluid invasion is very important in this type of reservoirs. The productivity benefits of underbalanced drilling are well known in the industry. When UBD is implemented correctly, it may considerably reduce or even eliminate mud invasion into the fracture systems. Even though UBD has many advantages over OBD, possible formation damage during UBD is crucial to judge the proper application of UBD.

Two main problems during UBD may cause severe damage around a well drilled with UBD [6]:

1. Temporary overbalanced condition.

2. Capillary imbibition.

In the first damage category, an overbalance pressure can be applied on the formation during short periods of time for various reasons like bit tripping or pipe jointing. Due to the lack of external protection cake, high filtration and mud invasion into the fracture and formation can occur, which decreases the fracture conductivity and plugs it. Mud invasion changes the relative permeability and wettability in the near wellbore region as phase trapping and solid retention in the fracture occurs. When the capillary force is important, counter-current imbibition occurs, with flow of reservoir fluid toward the well while the mud filtrate invades the formation [6].

This study focuses on the short overbalance conditions and time effects during UBD. The short overbalanced condition may cause deep invasion into the fracture system and result in a reduction of well productivity and reservoir recovery in the fractured formations.

\section{Experimental Procedure}

\subsection{Experimental Set-up}

Figure 1 shows a schematic of the apparatus used to study formation damage at NTNU. A Hassler type core holder was used in the experiment. This stainless steel core holder can accommodate up to $12 \mathrm{~cm}$-long and 3.8-cm-diameter cores. The core is mounted in a rubber sleeve and subjected to overburden (confining) pressure. One end piece of the core holder was fabricated to have two inflow 
ports and referred to as "invasion end". These ports were used to circulate the drilling fluids across the face of the core and to inject oil and brine as well. The other end piece, known as "production end", had only one inflow port to collect the filtrate/oil/brine, pumped from the invasion end.

Figure 1. The lay-out of experimental set-up for formation damage test.

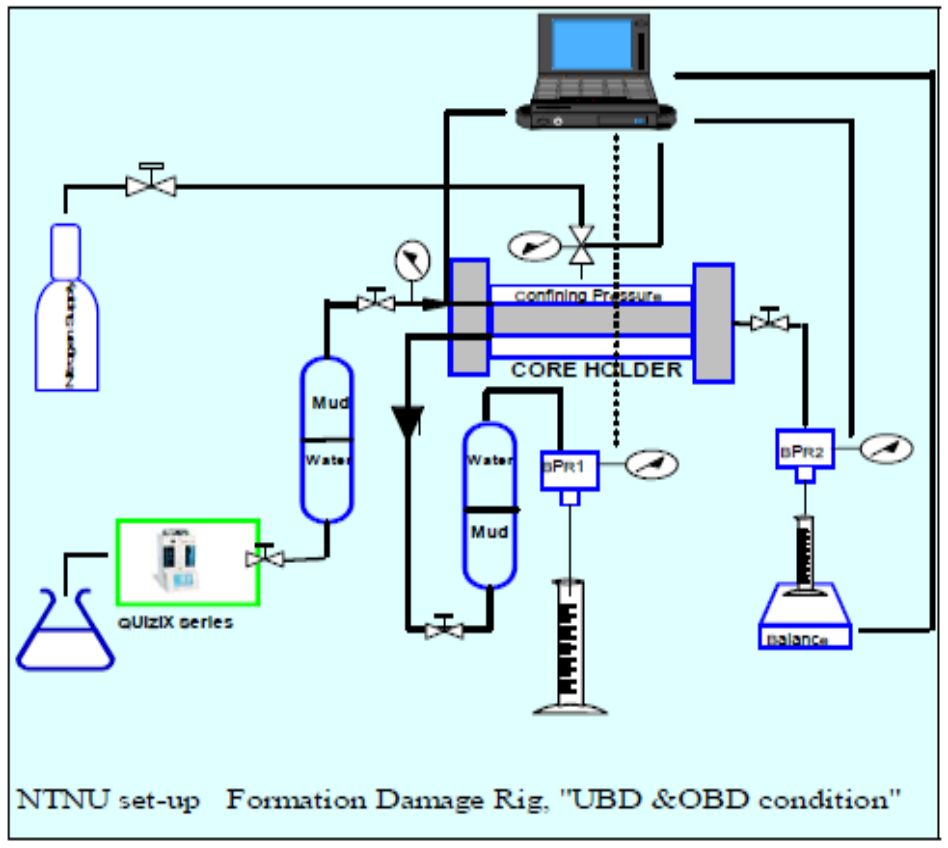

A stainless steel spacer-ring $1 \mathrm{~cm}$ in length was placed between the core face and the injection end to allow the mud to circulate and form cake on the core face. A transfer cylinder is employed to deliver mud, oil and brine to the core holder.

A Quizix pump, which could deliver fluids (mud, oil, brine) at a maximum flow rate of $50 \mathrm{~mL} / \mathrm{min}$ and maximum pressure of 10,000 psia, was connected to the transfer cylinder to deliver the fluids at the desired flow rate and pressure. Differential pressure meters were installed on both side of the core holder to measure differential pressure across the core. Back pressure regulators (BPR were installed at each end to control and maintain the desired pressure in the system by means of pressurized nitrogen gas. An electronic balance was used to collect the produced fluids. All the transducers and electronic balance were connected to a data acquisition card. This card sends all signals to the Labview software used for processing and plotting the data.

\subsection{Core Preparation}

Core samples from the Faxe outcrop in Denmark, which has similar rock properties to North Sea fractured reservoir have been used. The core samples $5-8 \mathrm{~cm}$ long and $3.8 \mathrm{~cm}$ in diameter were cut. The average lab oil permeability of the non-fractured cores is $3.9 \mathrm{mD}$ and the average porosity is $44 \%( \pm 5 \%)$. To create the fracture in the sample, it was cut along the core and a uniform fracture was thus created along the entire sample, giving a matrix and a small fracture along the core (Figure 2). Then the sample was mounted in the Hassler cell and confining pressure is applied to keep the two fracture faces together. This study is a research-based work and no reservoir temperature conditions were applied for the samples. 
Figure 2. The configuration of the fractured core sample.

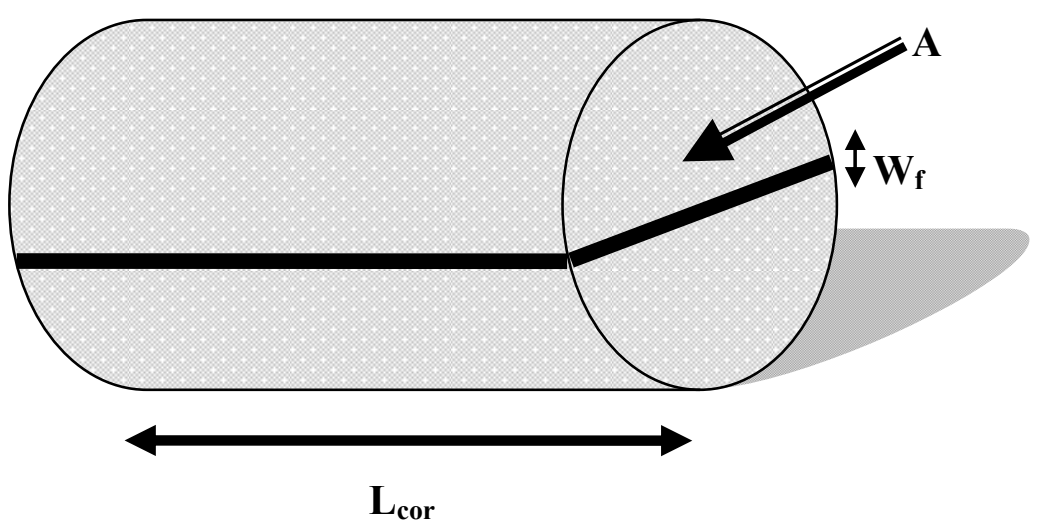

In the presence of two systems (matrix and fracture), permeability may be defined as matrix permeability, fracture permeability and system (fracture-matrix) permeability. Van Golf-Racht [7] has defined that the permeability of a fracture-matrix system may be represented by the simple addition of the permeabilities of matrix $k_{m}$ and fracture $k_{\text {eff: }}$.

$$
k_{m f}=k_{m}+k_{e f f}
$$

where: $k_{m f}=$ permeability of matrix and fracture, $\mathrm{cm}^{2}$;

$k_{m}=$ permeability of matrix, $\mathrm{cm}^{2}$;

$k_{\text {eff }}=$ permeability of fracture associated with rock-bulk, $\mathrm{cm}^{2}$.

Nevertheless, it must be redefined that the permeability of the single fracture is associated to the conductivity measured during the flow of fluid through a single fracture and independent of the matrix. This permeability, $k_{f f}$, is presented as:

$$
k_{f f}=\frac{w_{f}^{2}}{12}
$$

where: $k_{f f}=$ the permeability of the fracture, $\mathrm{cm}^{2}$;

$w_{f}=$ width of the fracture, $\mathrm{cm}$.

The relation between $k_{\text {eff }}$ and $k_{f f}$ will be described in the following equation. By substituting $A=\frac{\pi \cdot D^{2}}{4}$, the following equation for calculating of the fracture width is used:

$$
k_{\text {eff }}=\frac{w_{f}{ }^{3}}{3 \cdot \pi \cdot D}
$$

in which: $k_{\text {eff }}=$ the effective permeability of the fracture, $\mathrm{cm}^{2}$;

$w_{f}=$ the fracture width, $\mathrm{cm}$;

$D=$ the diameter of the sample, $\mathrm{cm}$.

Fracture dimensions and properties of samples used in this experiment are shown below (Table 1). 
Table 1. Fracture properties for formation damage test.

\begin{tabular}{ccccc}
\hline Sample No. & $\boldsymbol{W}_{\boldsymbol{f}}(\mathbf{c m})$ & $\boldsymbol{W}_{\boldsymbol{f}}(\boldsymbol{\mu} \mathbf{m})$ & $\boldsymbol{K}_{\boldsymbol{f} \boldsymbol{m}}(\mathbf{m D})$ & $\boldsymbol{K}_{\boldsymbol{f f}}(\mathbf{m D})$ \\
\hline UBD\#A & 0.001547 & 15.5 & 15.23 & 20,988 \\
UBD\#B & 0.0009337 & 9.3 & 6.22 & 7358 \\
UBD\#C & 0.0008079 & 8.1 & 5.39 & 5512 \\
UBD\#D & 0.000962 & 9.6 & 6.45 & 7829 \\
\hline
\end{tabular}

\subsection{Mud Circulation}

In a formation damage study with a specific task, for example, determine the impact of overbalance and underbalanced pressure on the invasion rate that is vital to keep the parameter numbers of the tests as low as possible. The number of variable parameters during the test may result in difficulties in the interpretation of the test results Therefore, the mud formulation was selected as simple as possible to avoid uncertainty in the results. This facilitates the interpretation of test results for the case of OBP and UBD conditions.

Drilling fluid was circulated across the saturated core at a constant flow rate of $0.5 \mathrm{~mL} / \mathrm{min}$ under different overbalance pressure conditions. A backpressure regulator was used to keep the core pressure at the desired level. When mud circulation starts, a mud cake begins to form on the face of the core and the filtrate starts invading the core. The core is allowed to develop a pressure gradient equal to the degree of overbalanced pressure expected during conventional drilling. Mudflow was regulated to simulate rates expected while drilling. The brine or lab oil was displaced by mud filtrate and the effluent was collected from the production end at desired time intervals ( $1 \mathrm{~min}$ ).

The filtrate was passed through a $0-15$ bar backpressure valve (as pore pressure) before accumulating in the collector. The drilling fluid was circulated under different overbalance pressures. The cumulative fluid loss was monitored and recorded during the test.

\subsection{Production Simulation-Back Flooding and Return Permeability Test}

After the placement of drilling fluid, it is important to simulate a return to production by flooding of fluid from formation side to wellbore side. A return permeability test consists in measuring permeability before and after exposing a rock core sample to the fluid. Once the leak-off has been completed, the permeability to oil, gas or brine is re-determined in the reverse flow direction to simulate production back out of the reservoir after the treatment. The permeability is determined after either of these methods.

1. Determination of flow rate at constant pressure (drawdown). Drawdown was performed by decreasing the pressure at the wellbore end of the plug and maintaining the formation end pressure at pore pressure allowing flow through the plug, mud cake and mud. The pressure drop was simulated to be that used in the reservoir. Drawdown was continued until a constant flow rate is achieved. Pressure and flow rate were measured by this procedure. 
2. Determination of differential pressure at constant flow rate. This procedure differs from the above by using a constant flow rate and measuring the corresponding differential pressures across the core. The flow rate was representative of the flux at the wellbore face. Flow was continued until constant pressure is achieved. The pressure required for the initiation of flow was recorded. Comparison between oil, gas or brine permeability, before and after fluid injection, make possible evaluation of the permeability reduction. The parameter Residual Permeability "return permeability" can be used to quantify the reduction caused by the tested fluid:

$$
\mathrm{RP}=k_{d} / k_{i}
$$

where: $k_{d}=$ oil or gas or brine permeability after leak-off test;

$k_{i}=$ initial oil or gas or brine permeability before leak-off test.

\subsection{Test Procedure}

A series of core-flood measurements were conducted on four fractured chalk-samples in an underbalanced leak-off test. After measuring the initial permeability, the drilling fluids were circulated at the wellbore face of the core holder under pressure conditions below core pressure. Then a series of return permeability measurements of lab oil were conducted at drawdown pressures ranging from 1 bar to the maximum 16 bar. This process represents the possible formation damage due to imbibition effects. The effect of an overbalanced "pulse" for $20 \mathrm{~min}$ is another measurement which was performed for all samples. This test is followed by a post overbalanced return permeability test at drawdown pressure the same as in the underbalanced core test. In both UBD and short pulse OBP four mud formulations are used, namely lab oil, brine $(3 \% \mathrm{KCl})$, water-based mud (bentonite with $\mathrm{XC}$ polymer) and fresh water. The following tables and figures illustrate the results of an underbalanced leak-off test and an overbalanced pulse during UBD core test.

The fracture apertures of the core samples were calculated to be in the $8-16 \mu \mathrm{m}$ range by Equations (2) and (3). This means the fracture is a micro-fracture and its size is a little bigger than the pore size of the chalk sample, which is reported as less than $6 \mu \mathrm{m}$.

\section{Experimental Results}

A set of experiments were carried out on four chalk-samples using different conditions. The results of all samples are included in the Discussion section of this paper.

\subsection{Chalk-Sample A}

Sample A. Tables 2 and 3 illustrate the results of an underbalanced leak-off test, combined with an overbalanced pulse using the lab oil as drilling fluid (the same as the saturation fluid). 
Table 2. UBD leak-off test with lab oil; Sample A.

\begin{tabular}{ll}
\hline Length & $6.85(\mathrm{~cm})$ \\
Diameter & $3.8(\mathrm{~cm})$ \\
Bulk Volume & $77.65(\mathrm{cc})$ \\
Porosity & 0.44 \\
Matrix Permeability & $3.86(\mathrm{mD})$ \\
Fracture width & $15.9(\mu \mathrm{m})$ \\
Circulation Rate & $0.5(\mathrm{cc} / \mathrm{min})$ \\
Test Temperature & Room Conditions \\
Confining Pressure & $24(\mathrm{bar})$ \\
Underbalanced Pressure (UBD) & $2.24(\mathrm{bar})$ \\
Overbalanced Pressure (OBP) & $2.04(\mathrm{bar})$ \\
Injected Fluid & Lab oil \\
Mud Type & Lab oil \\
Initial Permeability to Oil & $15.23(\mathrm{mD})$ \\
Fixed Initial Water Saturation & $0 \%$ \\
Overbalanced Pulse Duration & $20(\mathrm{~min})$ \\
\hline
\end{tabular}

Table 3. UBD leak-off test with lab oil; Sample A, Permeability Summary.

\begin{tabular}{lll}
\hline Test Phase & $\begin{array}{l}\text { Return } \\
\text { Perm. (mD) }\end{array}$ & $\begin{array}{l}\text { Return } \\
\text { Permeability (\%) }\end{array}$ \\
\hline $\begin{array}{l}\text { Underbalanced Mud Leak-off } \\
\text { Post UBD Return permeability (imbibition) @ }\end{array}$ & - & - \\
1 bar Drawdown & & \\
1.55 bar Drawdown & 15 & 98 \\
2.8 bar Drawdown & 15.21 & 100 \\
9.2 bar Drawdown & 15.61 & 102 \\
14.1 bar Drawdown & 17.5 & 115 \\
Overbalanced Pulse & 21.9 & 144 \\
Post OB Return permeability @ & - & \\
1 bar Drawdown & & \\
1.5 bar Drawdown & 16.8 & 110 \\
2.7 bar Drawdown & 16.7 & 110 \\
9.15 bar Drawdown & 17.64 & 116 \\
13.9 bar Drawdown & 18.75 & 123 \\
\hline
\end{tabular}

The permeability data of the Table 2 have been plotted and appear as seen in Figure 3. 
Figure 3. Permeability \& Drawdown in post UBD and OBP-sample A.

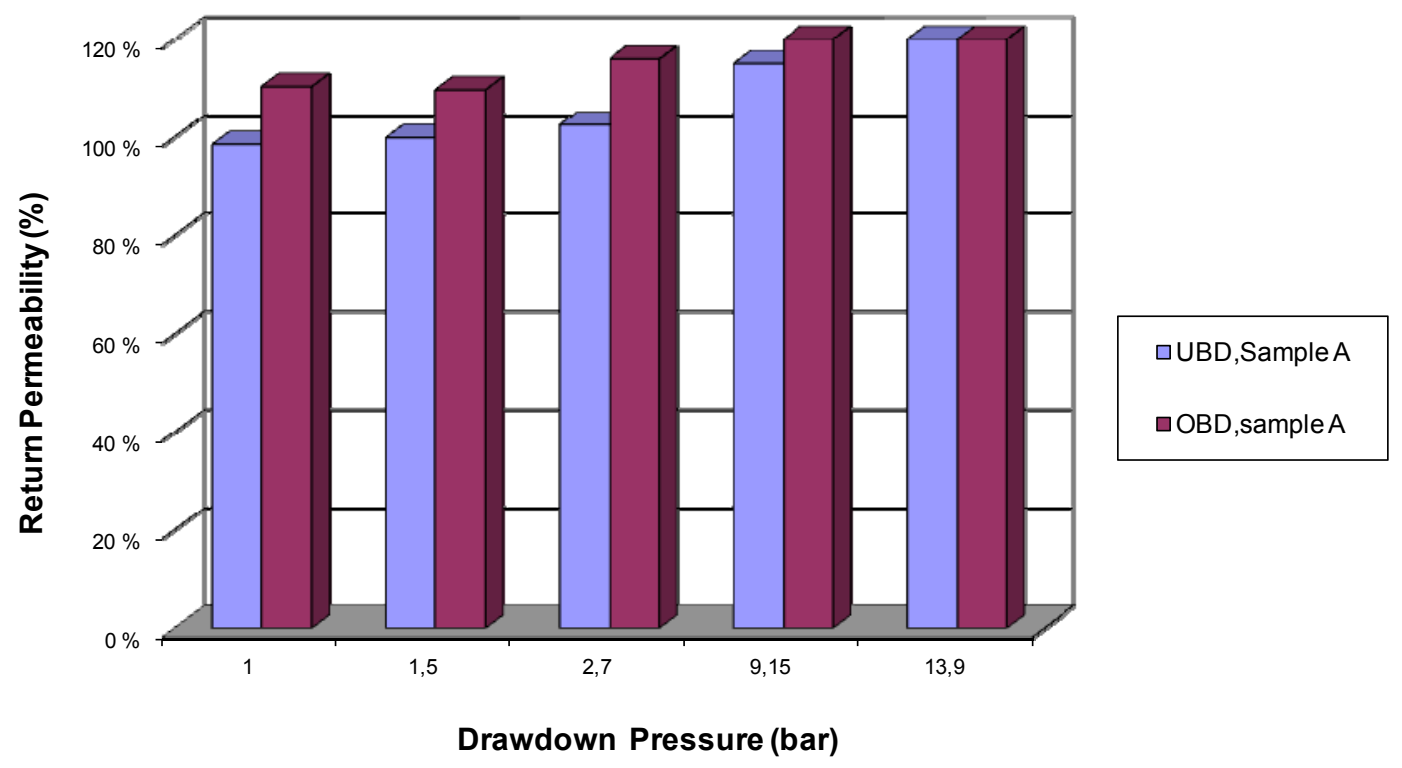

Examination of the data indicates that lab oil performed well as a drilling fluid during the test. At any drawdown pressure level under the UBD condition, full return permeability was attained. An overbalanced pulse of 6 bar for a 20-min period shows no reduction in permeability of the sample, as shown in Figure 3. This indicates that using the reservoir hydrocarbon as drilling fluid will result in minimum impairment of the formation.

\subsection{Chalk-Sample B}

Sample B. Tables 4 and 5 summarize the results from a second underbalanced leak-off test. Brine (water $+3 \% \mathrm{KCl}$ ) has been used as drilling fluid and circulated at underbalanced pressure conditions of approx. 2.1 bar. The permeability data of the Table 4 have been plotted and appear in Figure 4 .

Table 4. UBD leak-off test with brine; Sample B.

\begin{tabular}{ll}
\hline Length & $8.28(\mathrm{~cm})$ \\
Diameter & $3.8(\mathrm{~cm})$ \\
Bulk Volume & $93.86(\mathrm{cc})$ \\
Porosity & 0.44 \\
Matrix Permeability & $3.86(\mathrm{mD})$ \\
Fracture width & $9.4(\mu \mathrm{m})$ \\
Circulation Rate & $0.5(\mathrm{cc} / \mathrm{min})$ \\
Test Temperature & Room Conditions \\
Confining Pressure & $22.5(\mathrm{bar})$ \\
Underbalanced Pressure (UBD) & $2.1(\mathrm{bar})$ \\
Overbalanced Pressure (OB) & $6.24(\mathrm{bar})$ \\
Injected Fluid & Lab oil \\
Mud Type & Brine (water $+3 \% \mathrm{KCL})$ \\
Initial Permeability to Oil & $6.22(\mathrm{mD})$ \\
Fixed Initial Water Saturation & $0 \%$ \\
Overbalanced Pulse Duration & $20(\mathrm{~min})$ \\
\hline
\end{tabular}


Table 5. UBD leak-off test with brine; Sample B, Permeability Summary.

\begin{tabular}{lll}
\hline Test Phase & $\begin{array}{l}\text { Return } \\
\text { Perm. }(\mathbf{m D})\end{array}$ & $\begin{array}{l}\text { Return } \\
\text { Permeability (\%) }\end{array}$ \\
\hline Underbalanced Mud Leak-off & - & \\
Post UBD Return permeability (imbibition) @ & & \\
0.85 bar Drawdown & 5.96 & 96 \\
1.5 bar Drawdown & 5.81 & 93 \\
2.9 bar Drawdown & 6.01 & 96 \\
9.2 bar Drawdown & 5.99 & 96 \\
14.05 bar Drawdown & 6.17 & 99 \\
Overbalanced Pulse & - & \\
Post OB Return permeability @ & & \\
1 bar Drawdown & 0.35 & 6 \\
1.5 bar Drawdown & 0.59 & 9 \\
2.85 bar Drawdown & 0.94 & 15 \\
9.05 bar Drawdown & 1.67 & 27 \\
13.9 bar Drawdown & 2.43 & 39 \\
\hline
\end{tabular}

Figure 4. Permeability \& Drawdown in post UBD and OBP-sample B.

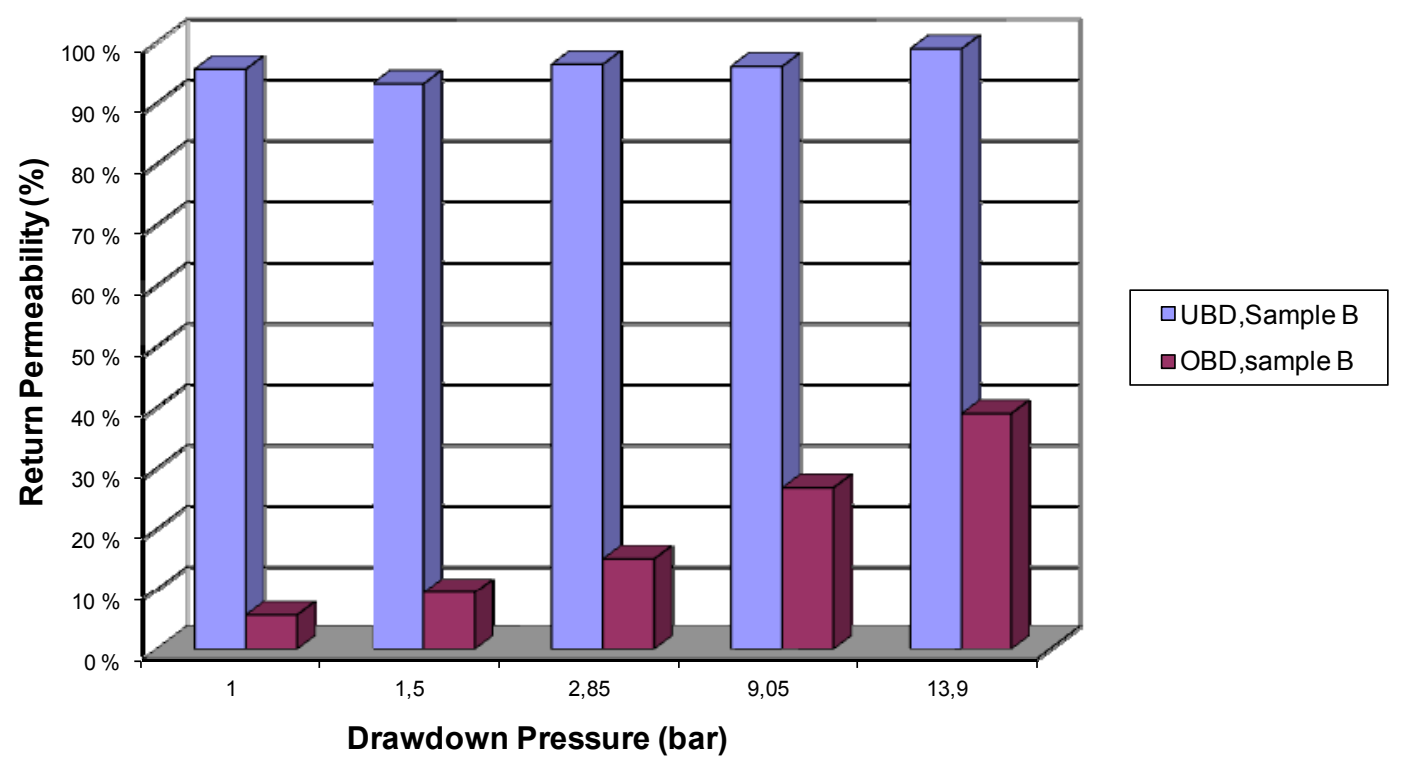

As shown in Figure 4, after exposure to the underbalanced condition the return permeability is about $96 \%$ of initial permeability, and by increasing the drawdown to 14 bar, $100 \%$ return permeability could been achieved. The effect of an overbalanced pulse incident is clearly illustrated by the application of a relatively moderate overbalance pulse for a period of only $20 \mathrm{~min}$ at 6.24 bar of overbalance pressure. A reduction of permeability up to about $95 \%$ has been observed. By increasing the drawdown pressure, the permeability of the sample improves. The highest drawdown of 14 bar gives the permeability of $2.4(\mathrm{mD})$, which is $38 \%$ of the initial permeability. 
A slight reduction in permeability to oil from $6.2 \mathrm{mD}$ before mud exposure to $5.9 \mathrm{mD}$ of observed, thus indicating that a small amount of counter-current imbibition of the mud has occurred (which may be attributed to the water-wet nature of the pore system). This reduction after UBD condition has been observed to be of up to $5 \%$. This damage could be avoided if the drawdown pressure were increased (14 bar drawdown gives 99\% return permeability). The main mechanism of damage in this case is migration of fines and it can reduce the permeability of the core significantly (by up to 95\%). As mentioned previously, the chalk-sample is water-wet and fines migration may occur in carbonate formations by migration of limestone grains. Fines migration will only occur when the wetting phase saturation becomes high enough. Here a high water saturation occurred due to invasion of water-phase in the drilling mud. It can be observed that if the velocity of the water phase becomes high enough, fines can migrate and be transported to blocking positions where significant reduction in permeability will occur.

\subsection{Chalk-Sample C}

Sample C. Tables 6 and 7 provide the results for an underbalanced/overbalanced comparative test conducted on a fractured carbonate (chalk) core sample containing lab oil. The drilling fluid which has been used during the test, was "water-based mud" (water, bentonite and XC polymer). The permeability data of Table 6 have been plotted and are shown in Figure 5.

Table 6. UBD leak-off test with water-based mud; Sample C.

\begin{tabular}{ll}
\hline Length & $6.23(\mathrm{~cm})$ \\
Diameter & $3.81(\mathrm{~cm})$ \\
Bulk Volume & $71(\mathrm{cc})$ \\
Porosity & 0.44 \\
Matrix Permeability & $3.86(\mathrm{mD})$ \\
Fracture width & $8.15(\mu \mathrm{m})$ \\
Circulation Rate & $0.5(\mathrm{cc} / \mathrm{min})$ \\
Test Temperature & Room Conditions \\
Confining Pressure & $22.5(\mathrm{bar})$ \\
Underbalanced Pressure (UBD) & $10.95-4.7(\mathrm{bar})$ \\
Overbalanced Pressure & $0.5(\mathrm{bar})$ \\
Injected Fluid & Lab oil \\
Mud Type & Base Mud + XC \\
Initial Permeability to Oil & $5.39(\mathrm{mD})$ \\
Fixed Initial Water Saturation & $0 \%$ \\
Overbalanced Pulse Duration & $20(\mathrm{~min})$ \\
\hline
\end{tabular}


Table 7. UBD leak-off test with water-based; Sample C, Permeability Summary.

\begin{tabular}{lll}
\hline Test Phase & $\begin{array}{l}\text { Return } \\
\text { Perm. (mD) }\end{array}$ & $\begin{array}{l}\text { Return } \\
\text { Permeability (\%) }\end{array}$ \\
\hline Underbalanced Mud Leak-off & - & - \\
Post UBD Return permeability (imbibition) @ & & \\
0.66 bar Drawdown & 4.49 & 83 \\
1.33 bar Drawdown & 4.72 & 88 \\
2.77 bar Drawdown & 4.79 & 89 \\
9.25 bar Drawdown & 4.70 & 87 \\
14.15 bar Drawdown & 4.65 & 86 \\
Overbalanced Pulse & - & \\
Post OB Return permeability @ & & - \\
0.61 bar Drawdown & 1.16 & 22 \\
1.43 bar Drawdown & 1.16 & 22 \\
2.35 bar Drawdown & 1.26 & 23 \\
9.27 bar Drawdown & 3.45 & 64 \\
14 bar Drawdown & 4.02 & 75 \\
\hline
\end{tabular}

Figure 5. Permeability \& Drawdown in post UBD and OBP-sample C.

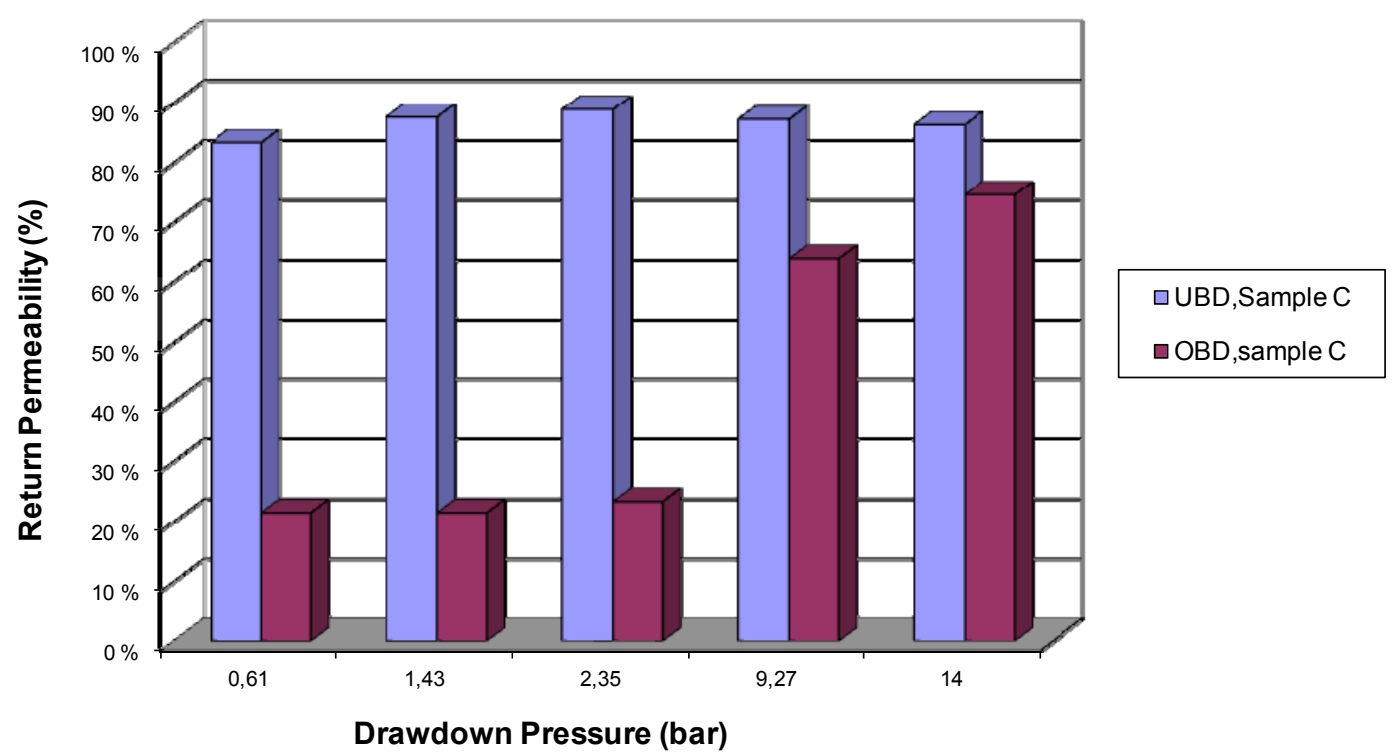

In this test during the UBD condition, the permeability under underbalanced and overbalanced conditions was monitored. Figure 6 provides a good indication of where the counter-current imbibition effects are expected to be problematic during the UBD process. The imbibition effects are apparent and cause a reduction in permeability when underbalanced pressure is reduced. This figure also illustrates that if imbibition effects are going to be problematic, how much underbalanced pressure gradient must be maintained to minimize their effect. In this test an underbalanced pressure gradient of about 5 bar is observed to be the optimal pressure condition for the UBD process. 
Figure 6. Monitoring of Permeability during UBD leak-off test on sample C.

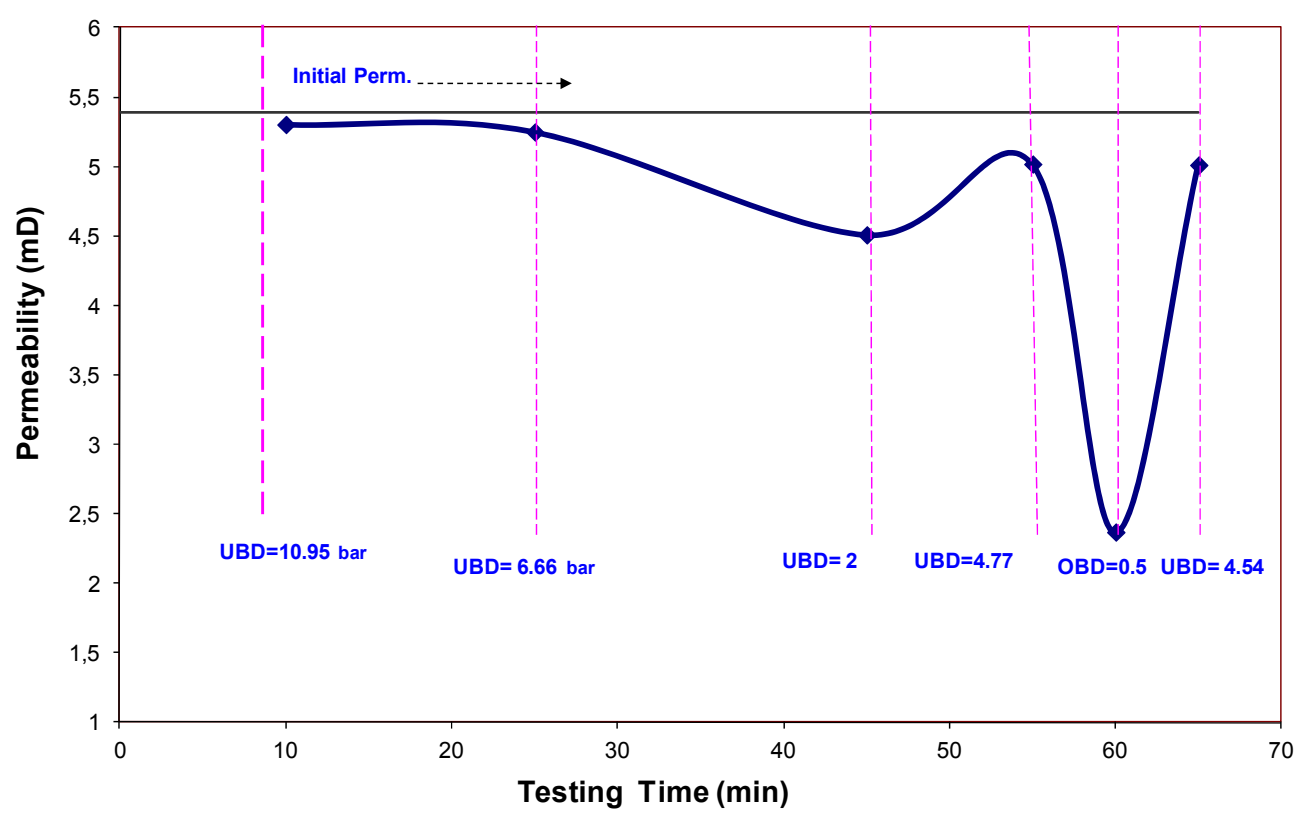

0.5 bar overbalanced pressure pulse leads to $50 \%$ reduction of the permeability. This may happen because of solid and mud filtrate invasion due to the absence of mud cake. Examination of the data indicates some impairment of the permeability after application of the UBD conditions. The permeability is reduced to $4.45(\mathrm{mD})$ by a drawdown of 0.7 bar, which means that the permeability impairment is $18 \%$ of the initial permeability. Increasing the drawdown at first gives some permeability improvement, whereby a 3 bar drawdown pressure results in the highest return permeability $(4.8 \mathrm{mD})$, however after this drawdown the permeability decreases when the drawdown goes up. At 14 bar drawdown pressure (the highest drawdown pressure value), the return permeability is about $4.65(\mathrm{mD})$. The permeability reduction up to about $18 \%$ thus seems to be attributable to spontaneous imbibition.

An overbalanced pulse of 6.2 bar for a 20 -min period shows about $80 \%$ impairment of permeability compared to the UBD conditions. Again, drawdown pressure has been applied to see the effect of drawdown on return permeability. As shown in Figure 8 the permeability remained constant until the drawdown exceed 2 bar, but after this drawdown the permeability started to increase with more drawdown pressure. The rate of improvement of permeability is much more from 2 bar to 10 bar drawdown pressure than from 10 to 14 bar. Ten (10) bar drawdown improved permeability to $67 \%$ of the initial permeability, and 14 bar drawdown results in just 7\% improvement, compared to 10 bar drawdown pressure.

After 14 bar drawdown pressure has been applied, any drawdown pressure less than this pressure shows almost the same (or more) permeability compared to 14 bar drawdown pressure. It means that once a high drawdown pressure is applied, lower drawdown pressures will have no effect on the permeability.

Another interesting result from Figure 7 is that a final permeability of approximately $4.2 \mathrm{mD}$ is measured. In this test, the drawdown pressure is reduced after post OB test, but the permeability remains constant at the same value as in the post OBD test. This means the drawdown pressure cannot change the permeability and it is the permanent permeability of the core. 
Figure 7. Hysteresis Effect -sample UBD_C.

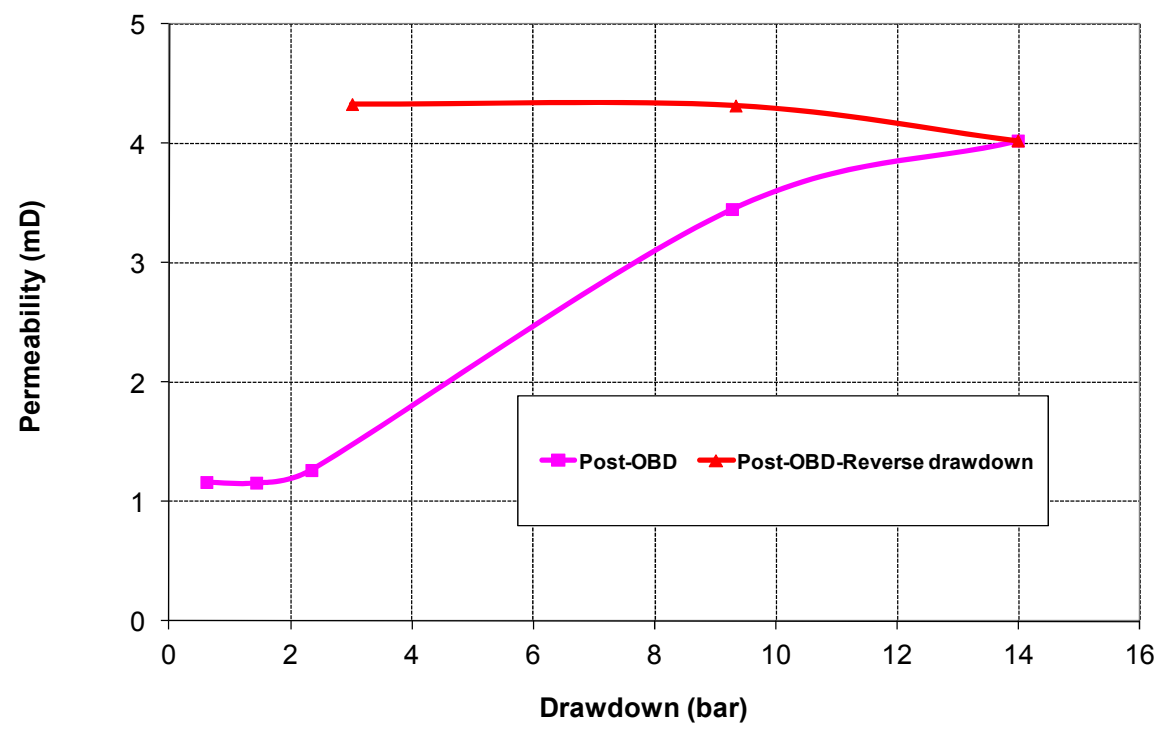

\subsection{Chalk-Sample D}

Sample D. Tables 8 and 9 summarize the results of combination of underbalanced/overbalanced fluid leak-off tests conducted on fractured carbonate (chalk) core samples. In this situation, fresh water has been used as drilling fluid for UBD and OBD and the effect of a loss of the underbalanced pressure condition during the drilling operations has been examined.

Table 8. UBD leak-off test with fresh water; on Sample D.

\begin{tabular}{ll}
\hline Length & $6.25(\mathrm{~cm})$ \\
Diameter & $3.7(\mathrm{~cm})$ \\
Bulk Volume & $67.17(\mathrm{cc})$ \\
Porosity & 0.45 \\
Matrix Permeability & $3.86(\mathrm{mD})$ \\
Fracture Width & $11.2(\mu \mathrm{m})$ \\
Circulation Rate & $0.5(\mathrm{cc} / \mathrm{min})$ \\
Test Temperature & Room Conditions \\
Confining Pressure & $20(\mathrm{bar})$ \\
Underbalanced Pressure (UBD) & $11-2.6(\mathrm{bar})$ \\
Overbalanced Pressure (OBP) & $6.2(\mathrm{bar})$ \\
Injected Fluid & Lab oil \\
Mud Type & Fresh Water \\
Initial Permeability to Oil & $6.45(\mathrm{mD})$ \\
Fixed Initial Water Saturation & $0 \%$ \\
Overbalanced Pulse Duration & $20(\mathrm{~min})$ \\
\hline
\end{tabular}


Table 9. Leak-off test with fresh water; sample D, Permeability Summary.

\begin{tabular}{lll}
\hline Test Phase & $\begin{array}{l}\text { Return } \\
\text { Perm. }(\mathbf{m D})\end{array}$ & $\begin{array}{l}\text { Return } \\
\text { Permeability (\%) }\end{array}$ \\
\hline Underbalanced Mud Leak-off & - & - \\
Post UBD Return permeability (imbibition) $@$ & & \\
0.66 bar Drawdown & 4.85 & 75 \\
1.36 bar Drawdown & 4.79 & 74 \\
2.83 bar Drawdown & 4.65 & 72 \\
9.03 bar Drawdown & 4.34 & 67 \\
13.75 bar Drawdown & 4.80 & 74 \\
Overbalanced Pulse & - & \\
Post OB Return permeability @ & & \\
0.36 bar Drawdown & 0.33 & 5 \\
0.81 bar Drawdown & 0.34 & 5 \\
2.1 bar Drawdown & 0.56 & 9 \\
9.05 bar Drawdown & 1.05 & 16 \\
13.36 bar Drawdown & 1.53 & 24 \\
\hline
\end{tabular}

Figure 8 presents the permeability profile during different UBD conditions. The permeability under some UBD conditions is increased in comparison with the initial permeability. This may be because water is unable to imbibe the core and flow is only controlled by the oil phase. A slight reduction in permeability can be seen even when a short overbalanced pressure of 0.64 bar is applied to the core. After this time, the reduction in permeability can be seen again, due to imbibition effects.

Figure 8. Monitoring of permeability during UBD leak-off test on sample D.

K-Measured during UBD Process

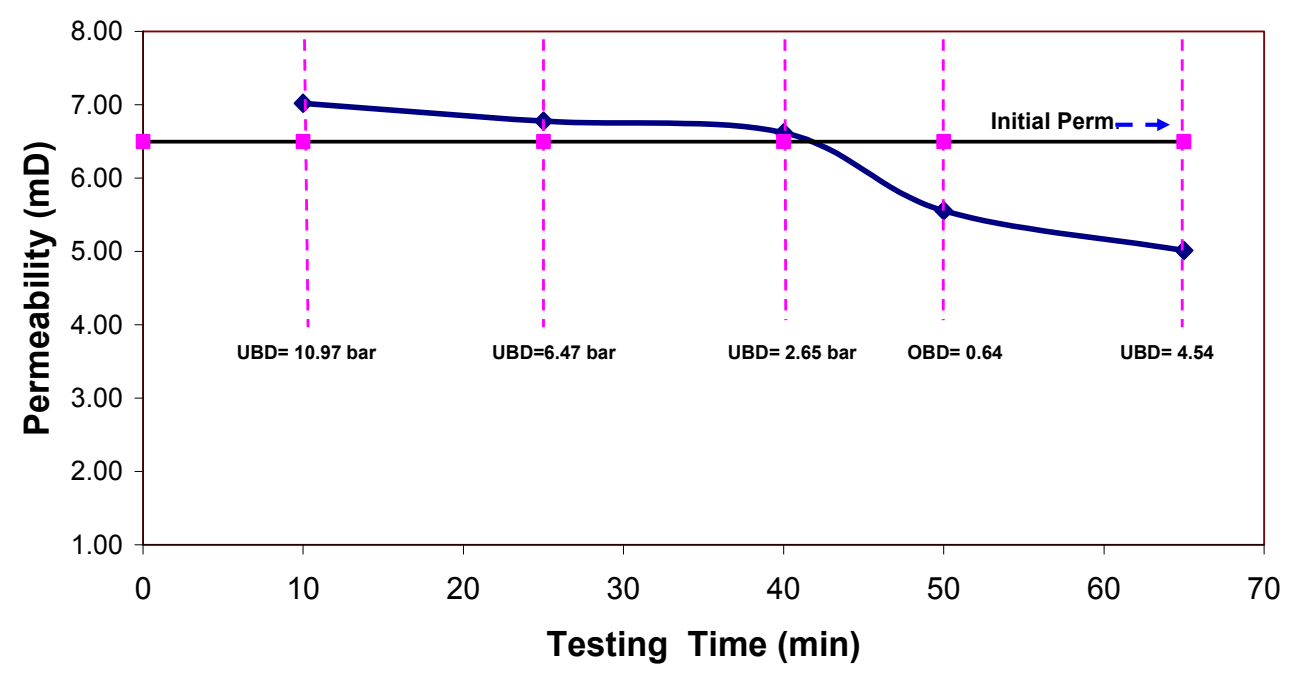

A series of permeability measurements were conducted at drawdown pressures ranging from 0.7 bar to the maximum drawdown pressure level of 13.8 bar after applying the UBD conditions. The results are summarized in Table 9 and Figure 8 and can be seen to vary from $4.3 \mathrm{mD}$ to $4.9 \mathrm{mD}$. A reduction in permeability with increasing drawdown pressure can be seen up to a drawdown level of 9 bar, and 
after this pressure, the permeability increases with increasing drawdown pressure. At 13.8 bar drawdown pressure, the permeability is almost equal to the one for 0.7 bar drawdown pressure. At these two drawdown pressures, the permeability is around $4.9 \mathrm{mD}$. A reduction in permeability from initial permeability of 6.07 to $4.9(\mathrm{mD})$ after $\mathrm{UBD}$, indicates that some amount of spontaneous imbibition of water filtrate has occurred.

The effect of an overbalanced pulse was illustrated by the application of overbalanced pulse for a period of $20 \mathrm{~min}$ at $6.2 \mathrm{bar}$ of overbalance pressure. The results of the post UBD return permeability test and also post $\mathrm{OB}$ are given in Table 9 and plotted in Figure 6. This Figure shows that permeability is significantly reduced when a relatively small period of overbalanced pressure is applied to the fractured core sample. It can be seen that a 95\% reduction in permeability has been observed up to 1 bar of drawdown pressure. Even at the maximum applied drawdown, pressure of 13.35 bar, only about $25 \%$ of the original permeability is returned.

In the end of the post $\mathrm{OB}$ drawdown test, the drawdown is decreased and the corresponding permeability is shown in Figure 9. This test was performed mainly to observe any hysteresis effects during production back flooding. It clearly demonstrates that drawdown effect can stimulate the core and permeability is increased, but not significantly.

Figure 9. Hysteresis effect on sample D.

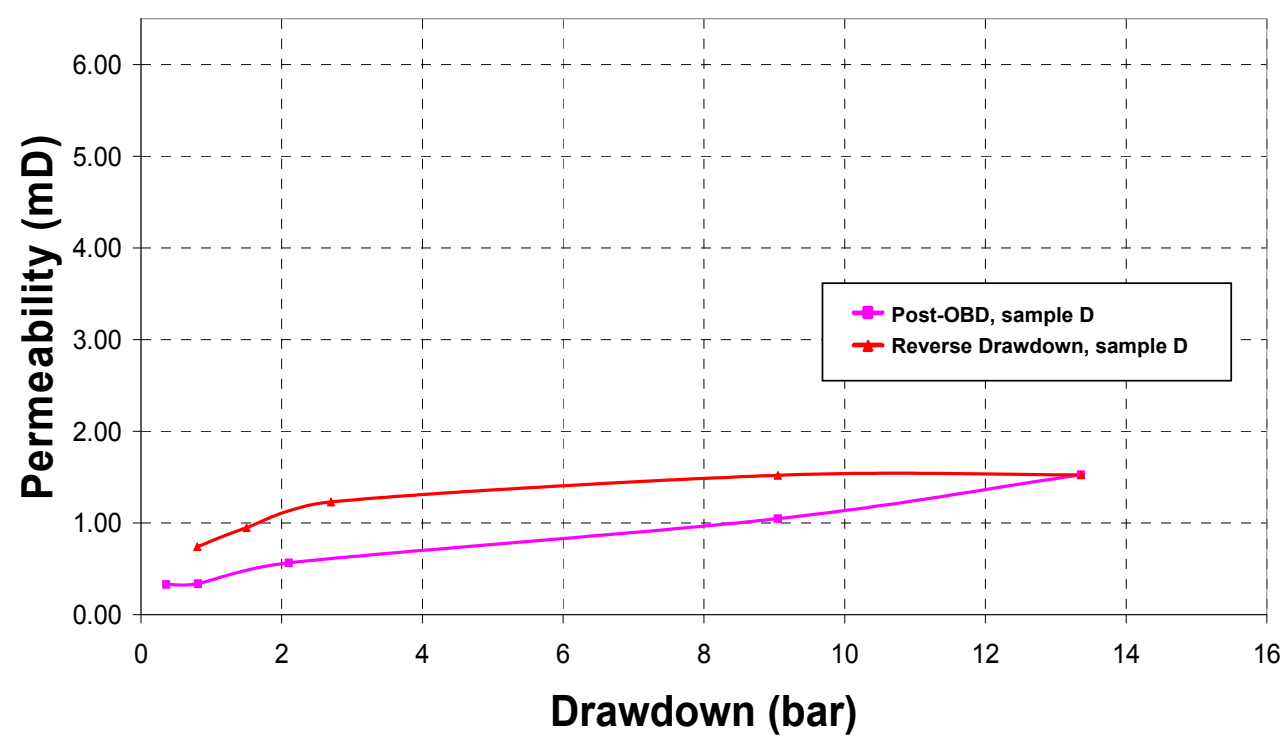

\section{Discussion of Results}

\subsection{Fracture Aperture Issues with UBD}

The presence of high permeability features in a formation, such as large naturally occurring fractures or extensive interconnected vugular porosity systems, represent a significant challenge for overbalanced drilling operations with respect to rapid and deep invasion and often significant permeability impairment. In some cases, if these fractures lead to overlying gas or underlying water and the majority of the production is expected to be associated with matrix production from the formation directly adjacent to the wellbore, then this may be advantageous. However, in most situations, we rely on the high permeability of these fracture and vug systems to act as conduits to feed 
gas or oil from a tight producing source matrix to the wellbore for production. This being the case, the preservation of the high permeability fractures and vugs is of prime importance.

These types of reservoirs may also be considered the prime potential candidates for UBD operations. However, if UBD is poorly designed, a short pulse OB pressure may cause invasion of large amounts of filtrate and potentially damaging solids into the near wellbore region, resulting in significant near wellbore damage. This deep damage is due to absence of any protective filter cake and bridging agent material during UBD operations. In this study the permeabilities of the fracture were measured in the $7000-20,000 \mathrm{mD}$ range and the opening fractures were $8-15.5 \mu \mathrm{m}$ in size. Therefore, any overbalance condition will show more invasion and change in formation permeability during back-flood production. All cases except case sample A show very a low return permeability after a short pulse of OB conditions. This may be disadvantage of a UBD operation when is compared to a condition of overbalance pressure. In case A, a low viscosity hydrocarbon was used as drilling fluid to facilitate this problem, and no change in return permeability after short OBD was observed.

\subsection{Optimized Underbalanced Pressure Gradient}

The screening of the permeability versus underbalanced pressure gradient provides a good indication if countercurrent imbibition effect could be problematic. It also indicates that an amount of underbalanced pressure must be maintained to minimize the formation damage. This is a very useful test as it allows the operator to conduct a risk assessment for evaluating the use of UBD technology in a given situation. Figures 6 and 8 present the results of the permeability profile where the UBD gradient is changing for samples $\mathrm{C}$ and $\mathrm{D}$, respectively. The capillary pressure curve for the chalk sample is given in Figure 13. In the cases where the capillary force between drilling fluid and oil phase is higher than UBD gradient, countercurrent flow from wellbore face to core occurs. This capillary effect has shown a reduction in the formation permeability and it was deceased as capillary force became high and underbalanced pressure was decreased. After the OB pulse, a cleanup process at underbalanced drawdown was performed and in the case C, most of damage was removed, but in case, D the damage removal was poor.

\subsection{UBD Fluid Selection}

Four different fluids were used as UBD fluids, namely: Case A: lab oil (as the same fluid for saturation of the core); Case $\mathrm{B}: 3 \% \mathrm{KCl}$ brine; Case $\mathrm{C}$ : water-based mud (bentonite and $\mathrm{XC}$ polymer); Case D: fresh water. Figure 10 shows the results of different UBD fluids and impact on return permeability. The lab oil, which was compatible with reservoir oil, shows the best performance during underbalanced conditions and no damage potential was determined. Low return permeability was measured when fresh water was used as UBD fluid. For scaling fresh water may be a good UBD fluid from a cost and general chemical compatibility point of view. The disadvantages of this fluid include potential for damage by contact with reactive clays and capillary imbibitions of fresh water to the formation. Oil produced from reservoirs by the UBD technique has many advantages with respect to compatibility with reservoir oil and costs. Viscosifiers such as silicones should be used to improve the poor rheology of this UBD fluid and to improve cutting transport. The UBD fluids selection results illustrate that proper selection of fluids is essential for successful underbalanced operation. 
Figure 10. UBD fluid selection.

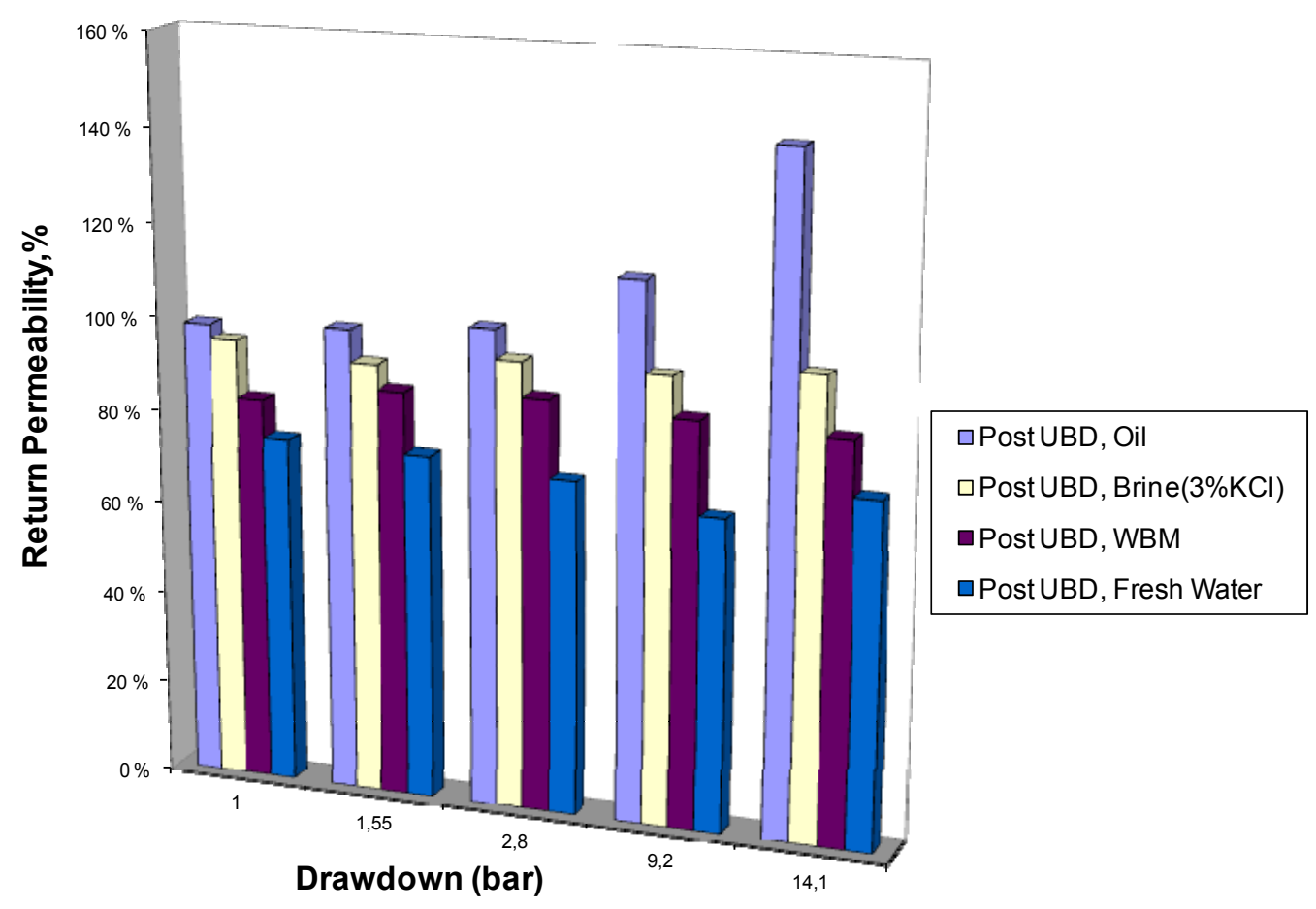

\subsection{Short Overbalanced Pressure Effect}

Figure 11 indicates that the significant formation damage appears when even short overbalanced pressure occurs. The magnitude of the damage depends on the type of fluid used and the fracture properties.

Figure 11. Return permeability results during short OB pressure.

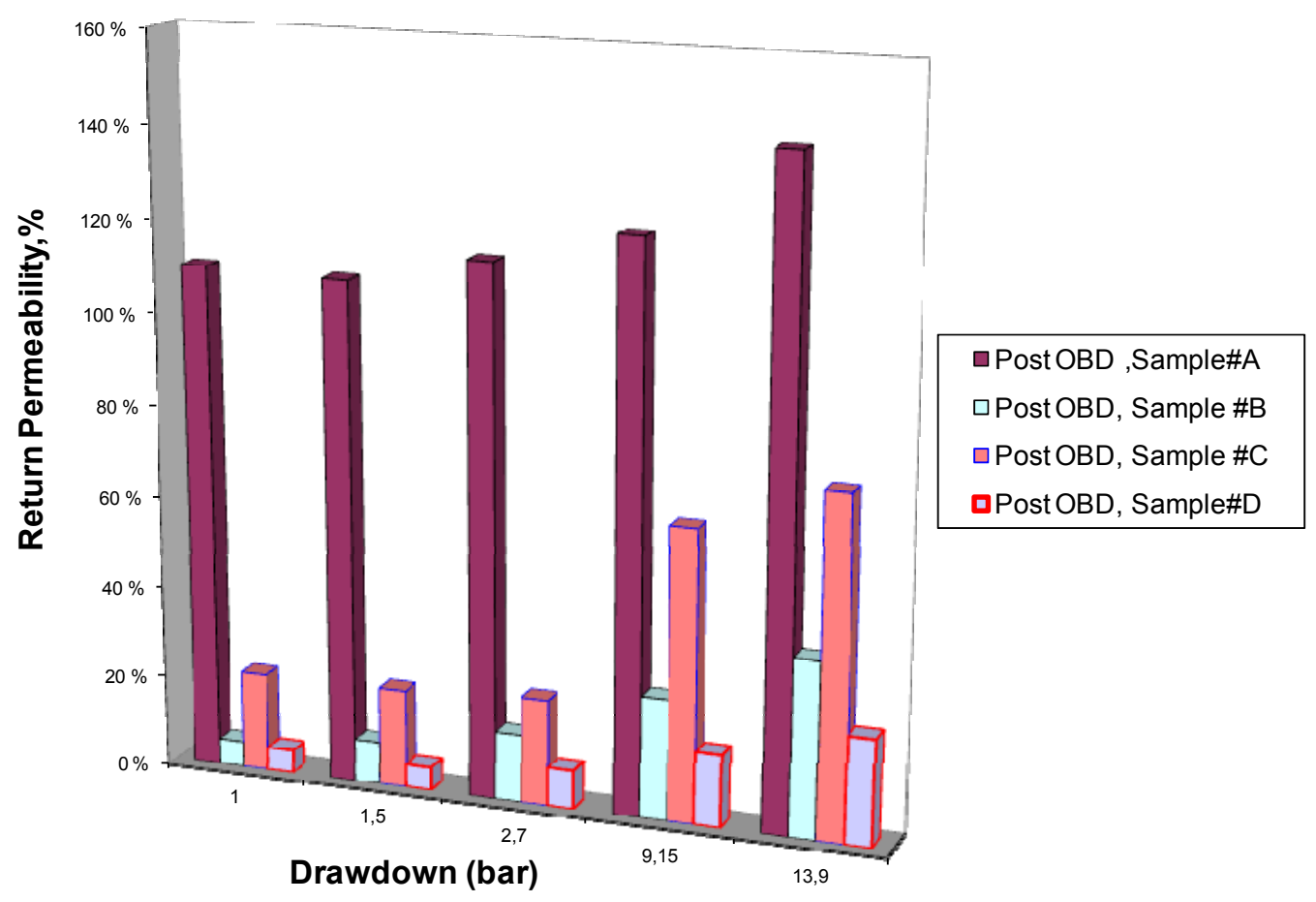


After the overbalanced pulse, three samples showed large reductions in permeability at low drawdown pressures and upon increasing the drawdown pressure return permeability values were not improved and permanent formation damage presented. The results show the effect of a loss of underbalanced pressure conditions on reduction of formation permeability. It describes how much the maintenance of underbalanced pressure in the fractured formation affects fluid invasion into the fracture and reduction of the productivity.

\section{Conclusions}

- Short overbalanced pressure during UBD conditions significantly reduced the formation permeability.

- Experimental results show that the minimum reduction in return permeability was observed when oil is used as drilling fluid.

- The screening of the permeability versus underbalanced pressure gradient provides a good indication of whether countercurrent imbibition effects could be problematic.

- The experimental results indicate to what degree the maintenance of underbalanced pressure in the fractured formation is important to avoid a large fluid invasion into the fracture.

- The results show that significant low return permeability was seen after a short pulse of OB conditions. This may be a disadvantage of a UBD operation when compared to overbalance pressure conditions.

\section{Acknowledgements}

The Norwegian University of Science and Technology (NTNU) is highly acknowledged for permission to publish this work.

\section{References}

1. Bennion, D.B.; Thomas, F.B. Underbalanced drilling of horizontal wells: Does it really eliminate formation damage. Presented at SPE International Symposium on Formation Damage, Lafayette, LA, USA, 7-10 February1994.

2. Lietard, O.; Unwin, T.; Guillot, D.; Hodder, M. Fracture Width LWD and Drilling Mud/LCM Selection Guidelines in Naturally Fractured Reservoirs. In Proceedings of the European Petroleum Conference, Milan, Italy, 22-24 October 1996.

3. Jiao, D.; Sharma, M. Mud-Induced Formation Damage in Fractured Reservoirs. SPE Drill. Complet. 1996, March, 11-16.

4. Ali, A.; Kalko, C.L.; Sing, U.B. A practical approach for preventing lost circulation in severely depleted unconsolidated sandstone reservoirs. SPE Drill. Complet. 1994, 9, 32-38.

5. Leoppke, G.E.; Glowka, D.A.; Wright, E.K. Design and Evaluation of Lost Circulation Materials for Severe Environments. J. Petrol.Technol. 1990, 42, 328-337.

6. Bennion, D.B. Thomas, F.B.; Bietz, R.F.; Bennion, D.W. Underbalanced Drilling, Praises and Perils: Lab and Field Experience. Presented at the SPE/CIM 5th One Day Annual Conference on Horizontal Well Technology, Calgary, Canada, 21 November 1995. 
7. van Golf-Racht, T.D. Fundamentals of Fractured Reservoir Engineering; Elsevier/North-Holland Inc.: New York, NY, USA, January 1982.

(C) 2011 by the authors; licensee MDPI, Basel, Switzerland. This article is an open access article distributed under the terms and conditions of the Creative Commons Attribution license (http://creativecommons.org/licenses/by/3.0/). 